Doris Gomes ${ }^{1}$

Flávia Regina Souza Ramos ${ }^{2}$

${ }^{1}$ Escola de Especialização em Odontologia Soebras, Funorte. R. Rafael da Rocha Pires 3913, Sambaqui. 88051-001 Florianópolis SC Brasil. dorisgomesodonto@ gmail.com

${ }^{2}$ Departamento de Enfermagem, Centro de Ciências da Saúde, Universidade Federal de Santa Catarina.

\title{
Subjetividade, ética e produtividade em saúde pós-reestruturação produtiva
}

\author{
Subjectivity, ethics and productivity \\ in post-productive health restructuring
}

\begin{abstract}
The scope of this paper is to analyze the ethical problems generated by the modern stressor pattern of post-transformation productivity in productive restructuring in the health area. It is a qualitative study of the descriptive and exploratory type in which 30 professionals (nurses, doctors and dental surgeons) from a metropolitan region in the South of Brazil were interviewed, all of whom had prior experience in the public and private sectors. The results were analyzed through Discursive Textual Analysis. Capitalization is revealed as a major ethical problem in the series of new issues derived from the productivity-profitability imperative in health, due to the acritical incorporation of ethics that is restricted to the company's interests or to corporate-individual interests. The ethical problem of low professional commitment to the needs of the patient and of the social collective indicates the need to build a new engaged solidarity in order to increase the quality of public healthcare. Productivity targeted at individual and social needs/interests in the area of health requires a new self-managing and collective engagement of the subjects, supported by an institutional and ethical-political effort of group action, cooperation and solidarity.
\end{abstract}

Key words Ethics, Job market, Health professional, Efficiency
Resumo $O$ objetivo deste artigo é analisar os problemas éticos gerados pelo padrão moderno -estressor de produtividade pós-transformações da reestruturação produtiva em saúde. Pesquisa qualitativa do tipo exploratório descritivo, em que foram entrevistados 30 profissionais [enfermeiros, médicos e cirurgiões-dentistas] de uma região metropolitana do sul do Brasil, com experiência de trabalho na área pública e privada. Os resultados seguiram a Análise Textual Discursiva. A capitalização é desvelada como importante problema ético na cadeia de novas questões advindas do imperativo produtividade-lucratividade em saúde, pela incorporação acrítica de uma ética restrita aos interesses da empresa ou corporativo-individuais. O problema ético do baixo comprometimento profissional às necessidades do paciente e coletivo social indica a necessidade de construção de uma nova solidariedade engajada para aumento da qualidade no atendimento público. Uma produtividade voltada ao cuidado às necessidades/interesses individuais e sociais em saúde solicita um novo engajamento autogestor e coletivo dos sujeitos, apoiado num esforço institucional e ético-político de grupalidade, cooperação e solidariedade.

Palavras-chave Ética, Mercado de trabalho, Profissional da saúde, Eficiência 


\section{Introdução}

A reestruturação produtiva como resposta à débâcle do welfare state, já ao final da década de 1960, se caracteriza pela incorporação de tecnologias informatizadas à produção com intensificação do trabalho na máquina, associado a novas técnicas de organização do processo de trabalho. O que ocorreu também no campo da saúde. No esgotamento da díade taylorismo/fordismo, a reestruturação alia a especialização flexível à precarização, com nova incorporação da subjetividade no trabalho pela autogestão. O que não significa, necessariamente, uma autorrealização do sujeito no trabalho, pois o cumprimento de metas da empresa através da superindividualização captura a subjetividade e transgride uma potencial (auto)transformação ${ }^{1}$.

A subjetividade como característica singular da pessoa, que a torna diferente das outras por seu registro emocional, afetivo e moral; a alteridade, ou intersubjetividade, que pode compreender, também, resistência e emancipação; a busca de autoexpressão como marca de identidade individual dentro de um coletivo; acabam plasmadas por estilos de vida a serem consumidos. Antes, o trabalho significava um laço social fundamental de aprendizagem da vida em sociedade e via de libertação da alienação e exploração, com a pós-reestruturação, a desregulamentação e a remercadorização das relações enfraquecem esse laço, contradizendo direitos de cidadania ligados ao estatuto do pleno emprego. Uma maior inclusão para o desenvolvimento através de políticas sociais é contraposta à ideia hegemônica de austeridade do Estado.

Segundo Jamenson², a desagregação desses laços societários estabelece um saber ideologizado e inquestionável de que mercado/consumo fariam parte da natureza humana, que nenhuma sociedade poderia funcionar eficientemente sem eles e que planejamento social seria, portanto, impossível. Agora, empreendedorismo, competitividade e produtividade são slogans de mudança necessária à sobrevivência no mercado. São inovações da reestruturação que não se restringem meramente ao campo organizacional e tecnológico, mas que se estendem ao metabolismo social. Um novo consentimento corpo-mente-alma do trabalhador é urdido no engajamento estimulado e integral a uma nova produtividade como valore-fetiche ${ }^{3}$, construída sob o medo do desemprego, gestão por competência e eficiência, intensificação do trabalho contra o desperdício e valor-dinheiro como referencial.
Ainda assim, o trabalho continua a exercer função central na sociedade moderna e identificando o trabalhador como ser da sociedade. Novos postos no campo da saúde são substancialmente ampliados cumprindo papel relevante na sustentação do emprego assalariado e no grau de formalização dos contratos de trabalho no Brasil ${ }^{4}$. Entretanto, a disputa em torno de escassos recursos públicos no complexo mix público-privado configura uma vulnerabilização dos profissionais no setor público, que não se sentem valorizados e identificados no trabalho, ocasionando novos problemas éticos em relação à qualidade -eficiência dos serviços prestados à população. $\mathrm{O}$ objetivo deste artigo, então, é analisar problemas éticos gerados pelo padrão moderno-estressor de produtividade em saúde pós-reestruturação produtiva, a partir de uma região metropolitana do sul do Brasil.

\section{Metodologia}

Pesquisa qualitativa do tipo exploratório-descritiva que privilegiou a manifestação dos profissionais da saúde sobre suas experiências de trabalho no mix público-privado, englobando: atenção primária, (poli) clínicas especializadas, consultórios, pronto-atendimentos, laboratórios de análise clínica e hospitais. Os dados foram coletados por meio de entrevista individual semiestruturada aplicada em 30 profissionais enfermeiros, médicos e odontólogos da região metropolitana de Florianópolis. A amostra foi iniciada com profissionais vinculados a uma Secretaria Municipal de saúde da região e definida pelo método bola de neve: um entrevistado inicial recomenda outro, repetindo-se o processo com novos incluídos até atingir o critério de saturação de informações.

$\mathrm{O}$ esclarecimento com anuência dos participantes (que são reconhecidos pela letra $\mathrm{P}$ mais numeração) foi acordado através do Termo de Consentimento Livre e Esclarecido. A participação ocorreu de forma voluntária e observando as condições de anonimato e autonomia propostos pela Resolução 196/96 do Conselho Nacional de Saúde. O projeto foi previamente aprovado pelo Comitê de Ética em Pesquisa com Seres Humanos da Universidade Federal de Santa Catarina.

O método de Análise Textual Discursiva ${ }^{6}$ organiza os resultados em torno de: desmontagem dos textos para formação de unidades base (corpus/dados); estabelecimento de relações entre essas unidades formando sistemas de categorias; captação do novo emergente com nova 
combinação de sentidos e compreensão do todo expressada num metatexto; e estabelecimento de um ciclo de análise do metatexto gerando resultados. Utilizou-se como auxiliar na categorização o software ATLAS.ti, desenvolvido para pesquisas qualitativas. $\mathrm{O}$ artigo focou a relação entre subjetividade, ética e produtividade.

\section{Resultados e discussão}

A diferença fundamental em termos de ideologia é a visão de produtividade de cada um, no setor público tu não tens esta preocupação tão grande com a produtividade, o lucro, a arrecadação. O setor privado é fundamentado na produtividade e na lucratividade que isto vai dar para a empresa. Um quer produzir muito e o outro não tem esta preocupação (P19).

Esta diferenciação na produtividade no mix público-privado em saúde, desvelada no discurso profissional, parece pautada na construção de um engajamento do trabalhador a novos valores da produção: é exigida nas relações de mercado uma "nova cultura" de competitividade, qualidade e modernidade no trabalho. Na saúde, o trabalho pode adquirir caráter produtivo dependendo do tipo de relação econômica que se estabelece: as relações de trabalho podem ser consideradas produtivas se resultarem na agregação de valor ao capital, se transformando em mercadoria capaz de produzir mais-valia no setor privado ${ }^{7}$. Neste sentido, o aumento da produtividade se torna essencial, porque muda a grandeza do valor de uma mercadoria: o tempo de trabalho necessário à produção muda com qualquer variação na produtividade, determinada pelas mais diversas circunstâncias como "a destreza média dos trabalhadores, o grau de desenvolvimento da ciência e sua aplicação tecnológica, a organização social do processo de produção, o volume e a eficácia dos meios de produção e as condições naturais".

No setor privado a gente é cobrado por muitas coisas: produtividade, eficiência até porque o nosso salário muitas vezes depende disto, você ganha por atendimentos a convênio, etc. (P20).

Segundo Pires ${ }^{9}$, o controle do processo de produção tornando o trabalhador dependente da venda de sua força de trabalho para sobreviver acontece através da divisão social do trabalho. Novas especialidades são ampliadas, demandadas cada vez mais pela interdependência e influência mútua entre os setores, gerando novas necessidades e profissões ou subprofissões. O profissional liberal especialista é considerado representante típico da civilização ocidental, com treinamento sistemático, capacidades intelectuais reconhecidas socialmente, renda significativa e controle de seu próprio processo de trabalho. Entretanto, a maioria desses profissionais ingressa no assalariamento na reestruturação, se tornando dependente de mecanismos gerenciais determinados pelas grandes instituições onde trabalham ou pela terceirização da administração - empresas de convênios e planos de saúde.

Mudanças na organização do trabalho apontam para modelos tipo toyotistas just in time, traduzidos como assistência lean à saúde. Apoiado na medicina baseada em evidências, o trabalho em equipe dentro de ambientes hospitalares procura reconhecer o desperdício e garantir cada ação e intenção focadas nas necessidades do cliente, minimizando o tempo de tratamento e suas etapas. Um plano de tratamento inicial feito coletivamente não é somente prescritivo seguindo "a ordem do médico", mas também preditivo, ou seja, trabalha com a previsão informada do andamento de todo tratamento, agora, colaborativo. As resistências a esta nova organização da produção para eliminação de desperdício, tempo, possibilidade de erros e, principalmente, dinheiro, com ampliação da satisfação do cliente e qualidade, esbarra numa autonomia médica historicamente autocrática e numa certa "inércia" de outras profissões, não acostumados à participação efetiva em processos decisórios ${ }^{10}$.

No setor privado eu era melhor remunerado, melhores condições de trabalho, mas a minha realização pessoal é maior no público, porque aqui a gente atende muitos que realmente precisam e isto te dá um retorno de bem estar que, muitas vezes, o dinheiro não dá. Eu não me sentia bem trabalhando nestas clínicas, você acaba atendendo muitos convênios, absenteísmos, são pacientes que muitas vezes te exigem isto, com os planos eles acabam te cobrando mais e essa é uma questão difícil de lidar, questão da ética (P20).

No assalariamento público-estatal o trabalho pode ser considerado essencialmente não produtivo, pois há troca do serviço por dinheiro como valor de uso, ou seja, sem produção de mais-valor ao capital. As políticas de ampliação de acesso aos benefícios sociais à maioria da população que constituíram variados sistemas universais de saúde a partir do welfare state keynesiano dos anos 1950 - realizado no Brasil somente na década de 80 -, amplificaram este tipo de assalariamento. Entretanto, apenas poucos países mantêm um formato de sistema nacional de saúde com prestação exclusivamente estatal que, normalmente, 
compete com um mercado em saúde crescentemente lucrativo. $\mathrm{O}$ direito universal à saúde tem sofrido contínua reestruturação: modificações no modelo de universalidade parecem se voltar a uma dualidade de sistemas - para pobres e para ricos ${ }^{11}$, consubstanciada no crescimento acentuado do mercado de seguros privados. Diferentes arranjos de governança estimulam o enxugamento de gastos com aumento de eficiência no trabalho pela introdução de mecanismos de mercado.

No Brasil, o engajamento social para a construção do SUS tem concorrido desde sua implantação com políticas depreciativas da dimensão coletividade-trabalho, contradizendo conquistas de cidadania: sucateamento da rede pública, baixo financiamento e sobreposição de outras lógicas de trabalho acionadas pelo capital, incluindo o estímulo produtivista acriticamente incorporado da lógica privada. Mesmo com mudanças políticas importantes nos últimos governos, um contexto de disputa público-privado constrói problemas éticos relacionados à produtividade/ eficiência no trabalho em saúde, abordados aqui como: capitalização e baixo comprometimento profissional.

A gente sabe que na clínica eles forçam um pouquinho mais que tu dê atestado, porque afinal de contas isto gera consulta, para o empregador quanto mais consultas melhor, então, eles sempre forçam que tu faças tudo que o paciente quer, mesmo que tu aches desnecessário. Por exemplo, um paciente que vem porque quer um exame, tu podes achar que aquele exame não é indicado naquele caso, mas tu sabes que vai ter alguém falando: este paciente quer, faz o que ele quer. Tu passas o tempo todo por estas questões (P13).

Minha colega falou que tinha 15 minutos para cada paciente, independente do que fosse fazer, tinha uma lâmpada que quando dava o tempo, eles ficavam acendendo (P10).

A possibilidade de autogoverno ou autonomia profissional que significa controle, mesmo que parcial, do próprio processo de trabalho, concorre com um novo engajamento produtivo subjugado aos interesses de mercado. Situações que confundem produtividade, assalariamento e capitalização evidenciam conflitos de interesse entre "dever ser" universal e códigos morais particulares das empresas, interferindo na decisão profissional: a atenção gerenciada coerciona a uma negociação utilitarista ativa sob a ética de mercado. Estabelece-se uma relação de produção que define a capitalização como: tirar partido ou proveito de ações na decisão em ato relacional profissional-paciente, objetivando aumento de capital. Como a produção e o consumo em saúde são simultâneos e relacionais, os próprios atos e efeitos do trabalho transformam-se em mercadoria produtora de lucro ao capital empregador privado.

As decisões profissionais subordinam-se à capitalização em situações onde: 1. é solicitada uma produtividade para ampliação do ganho na relação com planos ou convênios de saúde; 2 . é relacionado produtividade e remuneração do trabalhador; 3. as relações precarizadas de trabalho sustentam o medo da perda do emprego que pressionam a tomada de decisões; 4 . os interesses empresariais são assumidos como os próprios interesses profissionais - maior identificação do profissional com o capital que com o trabalho; 5 . as inovações tecnológicas e superespecializações sobrepõem interesses particulares às reais necessidades/interesses do paciente.

Eu percebia medo dos funcionários em perder o emprego. No privado as pessoas falavam: que bom que tu és efetiva na prefeitura, porque tu não tens esta preocupação de perderes o emprego aqui (P26).

No privado não sei se o pessoal é comprometido ou se é porque se não for trabalhar, der muito atestado, é demitido (P27).

Apesar do aumento substancial de postos de trabalho em saúde, novos constrangimentos ocasionados pelo aumento substancial do desemprego estrutural no país com deterioração das condições de trabalho e remuneração (especialmente em 1980-90), constroem uma precariedade subjetiva ao trabalhador. Consubstanciada como medo/pavor do desemprego e apoiada pelas novas tecnologias da comunicação e informação, um novo padrão moderno-estressor de produtividade é construído como novo valor-fetiche: um consentimento-adesão do trabalhador significa dedicação e engajamento total aos valores particulares da empresa. Uma nova inteligência reflexiva é solicitada, mas sob forte viés instrumental: dentro dos parâmetros morais, objetivos e valores institucionais, associados à alta produtividade guiada por interesses particulares ${ }^{3}$.

Uma produtividade naturalizada pelos vários vínculos empregatícios (o profissional à sua própria sorte no mercado); contratos de trabalho legais com baixa proteção social (flexibilização da regulação pública que demanda flexibilização de direitos); competitividade interpares para manutenção do status-quo no lugar de uma identidade de classe; e imperativo da lucratividade ou remuneração por resultados: aparece o profissio- 
nal-agenciador na relação com sistemas suplementares privados, orientando a produção para o tipo de financiamento que corresponda maior possibilidade de ganho ${ }^{12}$.

Aliado à gestão por competência e eficiência com intensificação do trabalho para eliminação do desperdício, essa nova atitude comportamental de autoempreendedorismo narcísico é estimulada como qualidade de um novo homem produtivo, responsabilizando-o por sua própria saúde e pela busca de conhecimento/aperfeiçoamento contínuo - ocultando sua incompatibilidade com a ascensão no mercado para todos. A hiperindividualização suplanta o mundo do trabalho e estende-se às relações afetivo-existenciais de vida, transformando o outro igual trabalhador - em inimigo: que compete e não se identifica. Dispositivos disciplinares associados ao trabalho que figuram como verdades a-históricas, naturalizadas nas relações de poder: de um lado atua a individualização liberal e, do outro, a totalização disciplinar ${ }^{3}$.

Me sinto mais cobrada no privado, horário, aparência, modo como estás vestido, se teu jaleco está bem passado, se está bem branquinho (P11).

Segundo Alves ${ }^{3}$, a autodisciplina como biopolítica conforma um tipo específico de indivíduo numa estrutura normalizada de gestos e pensamentos mais envolvente e mais manipulatória, porque penetra no âmago das instâncias do pré-consciente e do inconsciente. $\mathrm{O}$ inconsciente é ampliado, pois nele está contido o simbólico, o desconhecido, as representações-imagens que o indivíduo é estimulado a continuar ignorando. $\mathrm{O}$ pré-consciente que contém a utopia de um sonhar para frente, para uma possibilidade de futuro é capturado pela administração sob o estresse e o medo, impedindo uma vida cheia de sentidos, ampliando o sofrimento no trabalho e as novas doenças da alma.

A ética no privado é mais difícil, às vezes o chefe te cobra para pedir mais exames do plano para ti receber mais, ele te cobra uma coisa que eticamente não é correto. Na clínica tem uma pessoa que faz os RX que é difícil manter, às vezes vem dois chefes cobrando para ti pedir $R X$ sem necessidade, para repassar o valor e ele conseguir manter ela [máquina] lá. Por um lado, eu entendo, mas por outro, é completamente antiético, eu não posso pedir $R X$ sem realmente precisar ( $\mathrm{P} 11)$.

A construção de novas identidades profissionais, de usuários/pacientes e da organização no serviço pelas incorporações tecnológicas - em especial materiais -, reforça o conflito entre a lógica de cuidado-consumo de procedimentos, estabelecida pela biomedicina e a outra lógica, do cuidado-integralidade-necessidades sociais, da saúde coletiva - que revela os altos custos da primeira ${ }^{13}$. A compra e a incorporação desregrada de tecnologias de ponta por hospitais e clínicas privadas para satisfazer a lucratividade e o imaginário de desejo-satisfação do paciente construído sobre esse consumo tecnológico, parece resultado da ampla atuação da concorrência de mercado durante a construção do SUS. Um processo gerador de interdependência setorial no complexo industrial brasileiro que desconsidera necessidades sociais e diferencia os que podem ou não pagar pelo incremento ${ }^{14}$.

Numa perspectiva ética, a incorporação tecnológica sem planejamento orientado por necessidades reais e sem regulação efetiva do Estado - cada vez mais complexa por envolver uma pluralidade de agentes relacionados à política industrial, grupos financeiros e serviços pessoais - constrói conflitos de interesses na decisão profissional que acaba sendo, muitas vezes, baseada na necessidade de pagamento e manutenção desta tecnologia em detrimento da real necessidade de seu uso.

Tu sabes que ele tá preocupado como a rentabilidade da empresa, uma época eu trabalhei num convênio de planos de saúde onde eles terceirizavam os ambulatórios, se tu fosses muito bonzinho com os empregados no sentido de afastar muito do trabalho, tu estavas prejudicando a empresa, então, a gente fica num conflito de interesses e tentando ser o mais ético possível, porque tu tem que te preocupar com o teu paciente e não com o teu empregador, mas tu não podes deixar de lado né, se o empregador ficar insatisfeito, ele vai te colocar na rua (P13).

A ética é confundida, muitas vezes, com a organização e divisão de responsabilidades dentro da empresa, entendida como um código de ações definidos de acordo com os objetivos da instituição ${ }^{15}$. A ideologia da ética restrita acontece sob um permanente estado de insegurança que exige o máximo das potencialidades do profissional e uma superação sem descanso atrás da produtividade $^{16}$, num ambiente de exacerbada pressão gerencial e competitividade interpares. Situações macro que dialeticamente perpassam os atos no trabalho, propondo a questão: como fazer-se ético quando submetido a pressões permanentes por capitalização. O relativismo ético não consegue considerar a existência de bases morais universalizáveis construídas pela história humana que pressupõe vínculo com o passado e, ao mesmo tempo, com um projeto de futuro. Ao contrá- 
rio, se baseia na urgência pragmática do instante. Entretanto, a ética implica níveis diferenciados de reflexão, em que a ação solicita uma reflexão filosófica de modo mediato e seus sujeitos não podem prescindir de mínimos morais, ou seja, princípios, valores, atitudes e hábitos aos quais não se pode renunciar "sem renunciar, ao mesmo tempo, à própria humanidade" ${ }^{17}$. Há uma disputa cotidiana do agir ético sob a capitalização, que muitas vezes obnubila limites entre ética restrita, ética mínima e infração ética.

Veio um paciente para ser operado de duodenopancreatectomia. Orientado pelo cirurgião a procurar um gastroentereologista, este médico propôs outro procedimento. Só que o paciente já ia fazer uma cirurgia [eletiva] para resolver o problema em 3 dias. Aconteceu aí o que se chama de capitalização: o profissional que vai operá-lo mandou para um clínico que vai fazer outro procedimento, a meu ver, não indicado. Ele corre um risco desnecessário, porque o procedimento é sob anestesia geral, quando dali a 3 dias ele teria o problema resolvido. Mas o que é isto? Capitalização: fazer com que um colega ganhe dinheiro em cima de um paciente sem haver necessidade do procedimento (P 18).

Nesse caso, a capitalização acontece no faturamento de procedimentos desnecessários ou extras que favorecem ganho adicional a outro profissional. A superespecialização da saúde acabou criando uma modalidade de trabalho que se completa em si mesma, sem que seja necessário dar continuidade ao tratamento: os procedimentos9. O acesso privilegiado a um saber-fazer especializado leva o profissional a se utilizar desse subterfúgio de poder para auferir, a si ou a igual, algum tipo de lucratividade, mesmo em detrimento da verdade. Uma ética do "é o que há" é transformada em ideologia: há valorização do sucesso sob um saber-fazer especializado nos marcos do ideal liberal e de uma excelência produtiva centrada no pragmatismo, competência técnica e competitividade. Uma interface entre poder e saber que constrói verdades contidas nos próprios discursos científicos, vicejantes como única universalidade possível. Subsumida aos interesses de mercado e à hiperindividualização, esta interface substitui laços sociais por um mundo de átomos sociais sem ponto estruturante, sustentados pelo universo finito e imaculado do fetiche-dinheiro e pela angústia do narciso patológico como único afeto.

Para Zizek ${ }^{18}$ um indivíduo separado do conjunto social pelo aparente antagonismo inconciliável entre o eu e o todo, perde a dimensão do real com sentido, do viver em sociedade, para um real paralático, virtual. A biomoralidade centrada na prevenção do sofrimento e na felicidade como realização pessoal, forma contemporânea de transgressão ao imperativo moral, está condicionada às reações ético-emocionais testemunhadas individual e diretamente. Contraditoriamente, essa felicidade concorre com altos níveis de suicídio e medicalização para doenças da alma, onde a inveja assume papel central: o que conta não é tanto o que se possui, mas o que os outros possuem. Assim, são construídas zonas cinzentas de legalidade e corrupção com banalização e relativização de grandes atos, obscurecendo uma das maiores realizações da civilização: nossa sensibilidade moral espontânea.

Conflitos importantes permanecem pouco visíveis ao coletivo profissional por uma realidade esteticamente fragmentada, que encobre grandes vulnerabilidades sociais e alimenta a valorização da saúde e do corpo como objeto de troca mercadológica ${ }^{19}$. Uma capitalização na intersecção interespecialidades ou coersionada por uma gerência externa moderno-estressora funcionalista, fornece novos contornos à relação entre poder, normas e valores: a dimensão ética da verdade e da confiança no espaço de decisão profissional-paciente é cada vez mais reposicionada como desafio, numa ação que atesta diferentes conflitos de interesses e intencionalidades.

A aceitação totalizadora do mercado como regulador das vidas humanas releva a importância que o fetiche-dinheiro assume na contemporaneidade e, também, nos projetos ético-políticos relacionais da saúde coletiva.

Acho muito mais tranquilo trabalhar no setor público, não tem cobrança direta da instituição $e$ não tem concorrência entre si pela busca de pacientes ou procedimentos. Não há esta busca por honorários (P18).

Ao mesmo tempo em que um sentimento de desoneração da competitividade traz satisfação ao trabalhador no setor público, é perceptível um vácuo de responsabilidade na construção de parâmetros éticos coletivos de qualidade-eficiência, resultado da histórica disjunção existente entre gerência e trabalho.

A ética é um pouquinho complicado porque é basicamente a moral da coisa, então, você pode dizer que não há um estímulo para fazer com que o profissional produza bastante e ele não produzir muito, não é antiético e também não é ilegal (P19).

A lógica produtivista incorporada acriticamente do setor privado constrói metas de produtividade desconsiderando que o público-gratuito não está pautado na produção de mais-valia como 
no setor privado e que não existem as mesmas pressões de mercado nas relações de trabalho: valores-fetiche como imperativo da lucratividade, medo do desemprego e alta competitividade. Associado a um modelo gerencial centralizado, vertical e funcionalista que, normalmente, não incorpora os profissionais/trabalhadores como sujeitos ativos e autônomos do próprio processo de trabalho, se constrói uma precariedade subjetiva: um baixo comprometimento ético-político do profissional refletido na qualidade-eficiência dos serviços oferecidos à população.

Esta diferença de salário, de valorização, não quer dizer que tu tenhas que fazer que trabalha no público, não, eu acho que tu tens que produzir, não enrolar (P6).

O sentido positivo da estabilidade no emprego associado a problemas de remuneraçãovalorização, carreiras, formação-educação permanente e duplo vínculo, acaba distorcido pelo descomprometimento com valores próprios do trabalho público, transgredindo um engajamento pautado em sentimentos de solidariedade e justiça social, para além do meramente monetário e minimamente prescrito ${ }^{20}$. Alguns profissionais desonerados de um sentimento positivo de pertencimento e satisfação ao público-gratuito sentem-se desvalorizados, não reconhecidos e justificados em posturas pouco-produtivas, acomodadas, corpo mole.

É muito mais barato hoje para o governo pagar um hospital privado para fazer um procedimento, do que esse procedimento na própria instituição, mesmo pagando bem você não consegue fazer a estrutura andar, está emperrada numa UTI que não comporta o número de cirurgias, no corporativismo profissional. Já no hospital privado você tem que produzir se não é mandado embora e eles produzem (P19).

Como solução, a compra de serviços em saúde pelo Estado por mecanismos de contratualização passa a ser entendida como ação positiva às gerências que conseguem implantá-la: se pauta na ideia transformada em mito de que há ineficiência, menor agilidade e qualidade no serviço público em relação ao privado - confundida, boa parte das vezes, com a própria realidade. Essa mesma ideia associada à necessidade de ganho de resolutividade induz uma política de redução do Estado através da terceirização de administrações, traduzida como contratação das Organizações de Saúde (OSs) para as gerências de instituições públicas ${ }^{21}$.

Contraditória e ironicamente para Linhart ${ }^{16}$, o engajamento e a dedicação solicitados por essas administrações privadas se espelham em sentimentos percebidos nos funcionários do setor público (citadamente por trabalhadores franceses) identificados com o fazer para os outros, para a sociedade e numa lógica de conjunto - não corporativa, mas social. Engajamento emulado no coletivo que tem sido historicamente desvirtuado pelas administrações públicas brasileiras: vícios político-clientelistas, patrimonialistas e burocratizantes; sucateamento do público-estatal; descrédito do participativo-coletivo; e sobreposição de interesses privados sobre os públicos, construtores de profunda crise administrativo-gerencial.

No público a gente não se realiza, primeiro a questão de salário, não tem diferença se você se esforça ou não, você pode fazer um bom trabalho e ganhar $x$ e se você não se esforçar e fizer um trabalho mediocre você ganha o mesmo $x(\mathrm{P} 4)$.

Um estímulo à produção potencializado por gratificações de desempenho como ganho adicional pela introdução de legislações que agregam valor monetário ao "aumento de produtividade" já é prática corrente em alguns municípios, como Rio de Janeiro (RJ) ${ }^{22}$ e Canoas (RS). Um engajamento que aparenta mudança positiva na cobertura dos serviços, pois mesmo que as relações de produção no assalariamento público não envolvam produtividade-lucratividade, isto não significa ausência de exploração ou impossibilidade de remuneração adicional seguindo preceitos de a cada um segundo seu trabalho. Entretanto, este estímulo monetário por si só não demonstra ser suficiente, quando não tem significado uma transformação substancial da qualidade: a tradicional relação prescritivo-impositiva ainda se sobrepõe ao cuidado às necessidades/interesses do paciente $^{23}$.

Amplia-se a questão: os estímulos à produção no trabalho público devem ultrapassar o meramente monetário no sentido de uma eficiência produtiva como necessidade social, com transformação da qualidade do cuidado. Para tanto, a face cooperativa, público-social e democrático -participativa do processo de trabalho precisa ser amplificada, não somente para servir à elevação do potencial produtivo individual em si, mas à criação duma força qualitativa transformadora nova: a força coletiva. Uma mudança necessária que se estabelece na disputa entre lógicas distintas: um gerencialismo funcional-produtivista incorporado acriticamente do setor privado e gestões públicas qualificadas, orientadas por valores coletivos, cooperativos e solidários para produção de resultados pelo maior comprometimento profissional. 
Uma transformação da produção que esbarra na regulação débil do Estado sobre o trabalho em saúde, fortemente influenciado pelo mercado e pelas corporações profissionais (vínculos irregulares, heterogeneidade e precarização dos direitos) ${ }^{24}$ e numa realidade contraditória: 1 . gerências que permitam renormalizações de forma coletiva a partir de espaços públicos de debate e de redes de interfaces/interações entre sujeitos ${ }^{25}$, potencializadoras de modos coletivos singulares de fazer, ainda sofrem forte resistência de um saber/poder instituído e hierarquizado para ganho pessoal, corporativo ou empresarial, reprodutor de uma ideologia hedonista e relativismo ético; 2. a interdisciplinaridade como forma de produção coletiva e solidária, ainda concorre como ideal utópico com a hiperindividualização; fragmentação das especializações e novas tecnologias; hierarquias arraigadas e gerências que dificultam o espírito em equipe.

O trabalho no setor público é muito mais interessante, a equipe é maior, o contato com o ser humano também e isto melhora muito (P2).

Um profissional comprometido amplia sua capacidade autogestionária e cooperativo-solidária na renormalização entre trabalho prescrito e real, quando dribla condições adversas ou degradadas de trabalho em coletivos formais ou não formais, suscitando a questão: porque fazer dessa maneira e não de outra ${ }^{26}$. A tensão construída na deliberação com base em valores entre o uso que todo trabalhador faz de si pelos outros, como condicionante histórico produto e produtor de subjetividade, e o uso de si por si mesmo, como gestor do seu próprio trabalho, ultrapassa a ideia de passividade e mera reprodução do prescrito, com redução do sujeito a determinantes históricos e socioeconômicos ${ }^{27}$.

Entretanto, a disposição para esta renormalização voltada à solução das necessidades/ interesses do paciente e/ou coletividades requer engajamento individual e coletivo, sendo preciso investir em processos cooperativos gestionários e autogestionários de subjetivação, para recuperar a utopia do cuidado integral verdadeiramente centrado no paciente ${ }^{28}$, não meramente agenciado pela produtividade para diminuição do desperdício e aumento de capital, como na lógica de mercado. $\mathrm{O}$ trabalho com sentido de pertencimento a algo maior, coletivo e social, parece desempenhar papel essencial na elaboração permanente da subjetividade, permitindo que o trabalhador se aventure fora de si mesmo, inscrito numa história comum.
Um sentido molar coletivo e transformador incorporado nas mediações éticas profissionalpaciente pode reproduzir nos microespaços de poder a percepção do direito à saúde como social, da ideologia como um trespasse invisível de conceitos hegemônicos na ação cotidiana e do agente ético como sujeito consciente que sabe o que faz, que decide com liberdade e que responde com responsabilidade por sua ação $0^{15}$. Assim, uma formação-capacitação dialógico-relacional e ético-política solicita um comprometimento "gentificado" rumo à tomada de consciência do mundo, dos interesses historicamente negados, da presença do político e do libertário, dos sujeitos autônomos como fazedores de história ${ }^{29}$.

Quando a gente está numa gerência tudo muda, porque você é o cabeça, é responsável pelo desempenho, eu não imaginava ser tão difícil, porque o funcionário público é muito tranquilo e não adianta você impor, você tem que tentar convencê-lo de que não é assim. Quando eu entrei aqui era bem difícil a relação [com a gerência superior] porque tem muita questão política, não tenho dificuldade em acatar ordens, desde que não ultrapasse um limite [ético]. No setor privado por incrivel que pareça a gerência está mais perto da gente, está mais propícia a te ouvir ( $\mathrm{P} 25)$.

$\mathrm{O}$ apoio institucional público como facilitador de ações colaborativas de grupalidade e redes a partir de problematizações e experiências singulares locais que estimulam o protagonismo dos sujeitos ${ }^{30}$, parece exigir uma mudança cultural que possibilite alteridade, solidariedade, nova racionalidade comunicativa e engajamento coletivo. As gerências públicas precisam ser capacitadas às rupturas com antigos vícios e paradigmas funcional-produtivistas, agora voltados ao envolvimento dos profissionais/trabalhadores na gestão e tomada de decisão, comprometendo-os com os resultados assistenciais a serem alcançados. Uma produção em espaços de reflexividade sobre o próprio trabalho, que solicita resgate da dimensão coletiva não formal em reagrupamentos profissionais versáteis voltados à resolução real das necessidades/ interesses do paciente/usuário: visto não apenas como consumidor passivo de atos-produtos padronizados, mas como uma pessoa que apesar de vulnerada, tem interesse, opinião e expectativas. Assim, os parâmetros produtivos sob o valor como "algo pelo qual o cliente está disposto a pagar" voltados ao controle do desperdício e satisfação do cliente na organização enxuta-Lean, deve ser substituído por uma produção e autoprodução como nova excelência público-coletiva. 


\section{Conclusão}

A região metropolitana estudada é o maior aglomerado populacional do estado de Santa Catarina, apresentando diversificados serviços de alta complexidade de referência públicos e privados, com forte presença de duplo vínculo empregatício, o que muitas vezes confunde papéis e lógicas no cotidiano do trabalho profissional. Neste contexto, a ampliação da capitalização é desvelada como importante problema ético na cadeia de novas questões advindas do imperativo lucratividade/produtividade sob relações de mercado, pela incorporação acrítica de uma ética restrita aos interesses da empresa ou corporativo-individual. Há um contexto de falta de perspectivas sociais transcendentes à ordem estabelecida com intensificação do hedonismo em detrimento do sujeito reflexivo e do privado-liberal sobre o coletivo. A dimensão subjetiva assume caráter essencial sob um padrão produtivo pautado na "competitividade" e na busca da "excelência técnica", que quebra redes de solidariedade e mediações éticas comprometidas, influenciando também, o serviço público.

Este artigo pretende ampliar um importante debate: a necessidade do engajamento coletivo e solidário dos profissionais em saúde na reestruturação dos serviços, para construção de uma nova eficiência e qualidade no trabalho públicogratuito, não mais subsumido à lógica funcional-produtivista incorporada acriticamente do setor privado. Transformar o atendimento público em relações clínicas de excelência coletiva solicita capacitação a uma nova gerência democrático-inclusiva e nova dialogicidade para: equipes reconfiguradas pelas necessidades/interesses do paciente; cooperação interpares como força emuladora de potencialidades ético-político civilizatórias; gerências compartilhadas e comprometimento profissional, ao mesmo tempo técnico, humano e social, em espaço de produção, autoprodução e viver junto.

\section{Colaboradores}

D Gomes trabalhou na concepção e redação do artigo e FRS Ramos trabalhou na revisão crítica do artigo. 


\section{Referências}

1. Nardi HC. Ética, trabalho e subjetividade. Porto Alegre: Editora da UFRGS; 2006.

2. Jamenson F. O pós-modernismo e o mercado. In: Zizek S, organizador. Um mapa da Ideologia. Rio de Janeiro: Contraponto; 1999.

3. Alves G. Trabalho e subjetividade. São Paulo: Boitempo; 2011.

4. Moraes R, Galiazzi MC. Análise Textual Discursiva. Rio Grande: UNIJÍ; 2011.

5. Brasil. Ministério da Saúde (MS). Conselho Nacional de Saúde. Resolução no 196 de 10 de outubro de 1996. Diretrizes e Normas Regulamentadoras de Pesquisas Envolvendo Seres Humanos. Diário Oficial da União 1996; 16 out.

6. Dedecca CS, Trovão CJBM. A força de trabalho no complexo de saúde: vantagens e desafios. Cien Saude Colet 2013; 18(6):1555-1567.

7. Pena PGL, Minayo-Gomez C. Premissas para a compreensão da saúde dos trabalhadores no setor serviço. Saúde soc. 2010; 19(2):371-383.

8. Marx K. O Capital. Livro primeiro, volume I. Rio de Janeiro: Civilização Brasileira; 2006.

9. Pires DEP. Reestruturação produtiva e trabalho em saúde no Brasil. São Paulo: Annablume; 2008.

10. Troussain J, Gerard RA. Uma transformação na saúde. Porto Alegre: Bookman; 2012.

11. López-Fernandes LA, Millán JIM, Ajuria AF, Cerdá JCM, Suess A, Danet AD, Rodríguez MAP. Está em peligro la cobertura universal em nuestro sistema nacional de salud? Cac Sanit 2012; 26(4):298-300.

12. Bahia L. Alerta Vermelho. [acessado 2013 maio 20]. Disponível em: http://oglobo.globo.com/opiniao/alerta-vermelho-8357118

13. Trindade E. A incorporação de novas tecnologias nos serviços de saúde: o desafio da análise dos fatores em jogo. Cad Saude Publica 2008; 24(5):951-964.

14. Andreazzi MFS, Kornis GEMC. Padrão de acumulação setorial: finanças e serviços nas transformações contemporâneas na saúde. Cien Saude Colet 2008; 13(5):1409-1420.

15. Chauí M. Ética e Violência no Brasil. Rev Bioethikos 2011; 5(4):378-383.

16. Linhart D. Entrevista. Trab. Educ. Saúde 2011; 9(1):149160.

17. Cortina A. Ética mínima. São Paulo: Martins Fontes; 2009.

18. Zizek S. Em defesa das causas perdidas. São Paulo: Boitempo; 2011.

19. Berlinger G, Garrafa V. O mercado humano. Brasília: Editora da Universidade de Brasília; 2001.
20. Gomes D, Ramos FRS. Ética e comprometimento do profissional da saúde pós-reestruturação produtiva numa região metropolitana do sul do Brasil. Interface (Botucatu) 2014; 18(49):289-300.

21. Martins MIC, Molinaro A. Reestruturação produtiva e seu impacto nas relações de trabalho nos serviços públicos de saúde no Brasil. Cien Saude Colet 2013; 18(6):1667-1676.

22. Rio de Janeiro. Prefeitura. Lei 2285, de 4 de janeiro de 1995. Institui a Gratificação por Desempenho e Produtividade no Sistema Municipal de Saúde, cria o Fundo de Sobras de Produtividade e o Fundo de Reserva Anual de Produtividade, e dá outras providências. Diário Oficial do Rio 1995; 6 jan.

23. Merhy EE. Saúde e Direitos: tensões de um SUS em disputa, molecularidades. Saúde Soc 2012; 21(2):267-279.

24. Vasconcelos CM, Pasche DF. O SUS em perspectiva. In: Campos GWS, Bonfim JRA, Minayo MCS, Akerman M, Júnior MD, Carvalho YM, organizadores. Tratado de saúde coletiva. São Paulo: Hucitec; 2013.

25. Minayo-Gomez C, Barros EB. Saúde, trabalho e processos de subjetivação nas escolas. Psicol. Reflex. Crit. 2002; 15(3):649-663.

26. Scherer MDA, Pires D, Schuartz Y. Trabalho coletivo: um desafio para a gestão em saúde. Rev Saude Publica 2009; 43(4):721-725.

27. Neves TP. A incorporação da abordagem ergológica na formação dos profissionais de saúde: em busca da integralidade da atenção à saúde. Rev. APS 2010; 13(2):217223.

28. Franco TB, Mehry EE. Trabalho, produção do cuidado e subjetividade em saúde. São Paulo: Hucitec; 2013.

29. Freire P. Pedagogia do compromisso. São Paulo: Villa das Letras; 2008.

30. Barros MEB, Guedes CR, Roza MMR. O apoio institucional como método de análise-intervenção no âmbito das políticas públicas de saúde: a experiência em um hospital geral. Cien Saude Colet 2011; 16(12):48034814.

Artigo apresentado em 12/03/2014

Aprovado em 01/12/2014

Versão final apresentada em 03/12/2014 